\title{
STANDARDISATION AND PHYTOCHEMICAL SCREENING OF TRADITIONAL FORMULATION
}

\author{
SRI KAMATCHI PRIYA RAMAMOORTHYa, DIWAKAR MANICKAMb, SAMU SUBRAMANIAMc* , SHYAMA \\ SUBRAMANIAMd
}

\begin{abstract}
a,bDepartment of Biochemistry, Regenix Super Speciality Laboratories, Chennai, Tamilnadu, India, cHead of the Department, Department of Biochemistry, Regenix Super Speciality Laboratories, Chennai, Tamilnadu, India, dConsultant, Lab Services, Apollo Hospital, Chennai, Tamilnadu, India
\end{abstract}

Email: subramaniam@regenix.in

Received: 23 Sep 2016, Revised and Accepted: 15 Nov 2016

\section{ABSTRACT}

Objective: The main objective of this study is to standardise and evaluate traditional formulation both qualitatively and quantitatively on the basis of organoleptic characteristics, physical characteristics, physiochemical properties and phytochemical screening.

Methods: Traditional formulation (TF) containing seven traditionally used herbs were collected from local areas and market. The plants were washed, airdried and coarsely powdered. The aqueous extract was prepared as per literature, and various physiochemical, phytochemical screening was done.

Results: The organoleptic character shows the drug with greenish colour, slightly bitter taste and characteristic odour. The physiochemical properties show the appropriate $\mathrm{pH}$ and the solubility of TF. Secondary metabolites like phenolic compounds and flavonoids are present abundantly in aqueous extract than in other extracts.

Conclusion: Our studies suggests that TF contains medicinally important secondary metabolites which has disease protective properties. This study will help in the progression of a suitable monograph, determining the quality and purity of a crude extract and laying down pharmacopoeia standards for the formulation.

Keywords: Traditional formulations, Organoleptic character, Physiochemical, Phytochemical screening.

(C) 2016 The Authors. Published by Innovare Academic Sciences Pvt Ltd. This is an open access article under the CC BY license (http://creativecommons.org/licenses/by/4.0/] DOI: http://dx.doi.org/10.22159/ijcpr.2017v9i1.16617

\section{INTRODUCTION}

The quality assessment of herbal formulations is of vital importance in order to justify their acceptability in the modern system of medicine. Herbal formulation is usually prepared with the combinations of individually extracted single herbs to get the benefit of synergism or to prevent side effect arising from the chief herb. One of the major problems faced by the herbal industry is the unavailability of rigid quality control profiles for herbal materials and their formulations [1]. Regulatory bodies have laid down the standardisation procedures and specifications for Traditional Siddha formulation [2]. India transpires as the major country and plays the lead role in the production of standardised, therapeutically effective traditional formulations in the world market. The World Health Organization (WHO) has appreciated the importance of medicinal plants for public health care in developing nations and has evolved guidelines to support the member states in their efforts to formulate national policies on traditional medicine and to study their potential usefulness including evaluation, safety, and efficacy. Quality evaluation of herbal preparation is a fundamental requirement of industry and other organisation dealing with Siddha and herbal product [3]. The process of standardisation can be achieved by stepwise pharmacognostic and phytochemical studies.

Phytochemicals are natural and non-nutritive plant bioactive chemical compounds that have protective or disease preventive properties against external stress and pathogenic attack [4]. Nowadays, traditional medicinal practices form an integral part of complementary or alternative medicine. The plant-derived phytochemicals with therapeutic properties could be used as a single therapeutic agent or as combined formulations in drug development [5]. The choice of technique depends largely on the solubility properties and volatilities of the compounds to be separated. The phytochemical investigation ofa plant may involve extraction of plant materials, phytochemical screening, separation and isolation of the constituents, characterization of the isolated compounds [6]. Liver has a pivotal role in the maintenance of normal physiological process through its multiple and diverse functions, such as metabolism, secretion, storage and detoxification of a variety of drugs. It is exposed to a wide variety of xenobiotic, hepatotoxins and chemotherapeutic agents that lead to damage and subsequent impairment of its function.

Therefore herbal and other indigenous sources have been adequately explored for the safe and effective hepatoprotective action. In the absence of reliable liver protective drugs in modern medicine, in India, a number of medicinal plants and their formulations are used to cure hepatic disorders in traditional systems of medicine [7]. There are numerous plants and traditional formulations available for the treatment of liver diseases. Treating liver diseases with botanical drugs has a long tradition, but evidence for efficacy is sparse. Moreover, synthetic drugs available in the market may cause serious side effects. To pursue scientific proof, the present work is designed and screened with the seven medicinal plants, which were used traditionally for treating liver disorders.

\section{MATERIALS AND METHODS}

\section{Plant materials}

Traditional siddha formulation consists of 7 ingredients, viz., Curcuma longa Terminaliachebula, Terminaliabelerica, Emblicaofficinalis, Sp hagneticolacalendulacea Phyllanthusamarusand Cuminumcyminum. These plants have antibacterial, hepatoprotective, antihepatotoxic, uterine and intestine stimulating properties. These plants have been referred from the text "Gunapadam"first edition, 1936 (Siddha Materia Medica) written by Vaidya Ratnam K. S. Murugesa Mudaliar [8]. All these plant parts were procured from the field and local market and were authenticated from Siddha Central Research Institute, Arumbakkam, Chennai.

\section{Preparation of traditional formulation (TF)}

The formulation was prepared as per the Traditional Siddha System of medicine. All the ingredients were powdered separately, passed through 100 \# sieve and then mixed together in equal proportions to 
get uniformly blended formulations. $10 \mathrm{~g}$ of TF was boiled in $500 \mathrm{ml}$ of distilled water for 1 hour. Filtrate was evaporated to dryness under vacuum at $50{ }^{\circ} \mathrm{C}-55{ }^{\circ} \mathrm{C}$ using a rotatory evaporator under reduced pressure. The yield of the preparation of TF was 5.3g. Evaporated extracts were reconstituted in water [9].

\section{Standardization properties}

The various standardisation parameters studied were organoleptic properties, Physiochemical investigations, determination of $\mathrm{pH}$, Fluorescence analysis, Preliminary Phytochemical analysis, and determination of moisture content, viscosity, surface tension and density, determination of physical characteristics of the powder formulation.

\section{Organoleptic evaluation}

Organoleptic evaluation refers to evaluation of the formulation by color, odour, taste, texture, etc. The organoleptic characters of the samples were evaluated based on the method described by Siddiqui et al. [10].

\section{Physico-chemical investigations}

Physico-chemical investigations of formulations were carried out, including the determination of extractive values and ash values [11-12].

\section{Moisture content}

An accurately weighed $1 \mathrm{~g}$ of traditional formulation powder was taken in a tarred glass bottle. The crude drug was heated at $105^{\circ} \mathrm{C}$ in an oven till a constant weight was obtained. Percentage of the moisture content of the sample was calculated with reference to the air-dried drug. Moisture content was determined by loss on drying method (LOD). The technique has been accepted as an official method for evaluation by various pharmacopoeias. One gramme of the TF was taken and kept for $24 \mathrm{~h}$ in a graduated, stoppered cylinder, in contact with the water up to the mark of $20 \mathrm{ml}$. After 24 $\mathrm{h}$ the increase in volume was noted.

\section{Determination of Ash values}

\section{(i) Determination of total ash}

Accurately weighed $2 \mathrm{~g}$ of traditional formulation powder was added in a crucible at a temperature of $400-600^{\circ} \mathrm{C}$ in a muffle furnace till carbon-free ash was obtained. It was calculated with reference to the air-dried drug.

\section{(ii) Determination of acid insoluble ash}

Ash above obtained, was boiled for $5 \mathrm{~min}$ with $25 \mathrm{ml}$ of $1 \mathrm{M}$ Hydrochloric acid and filtered using an ashless filter paper. Insoluble matter retained on filter paper was washed with hot water and filter paper was burntin a muffle furnace. The percentage of acid insoluble was calculated with reference to the air-dried drug.

\section{(iii) Determination of water soluble ash (WSA)}

Ash was boiled for $5 \mathrm{~min}$ with $25 \mathrm{ml}$ of water. The insoluble matter was collected in a Gooch crucible or on an ashless filter paper, washed with hot water and ignited for $15 \mathrm{~min}$ at a temperature not exceeding $450{ }^{\circ} \mathrm{C}$. The weight of insoluble matter was subtracted from the weight of the ash, the difference in weight represented the water-soluble ash. The percentage of water-soluble ash was calculated with reference to the air-dried drug.

\section{(iv) Determination of $\mathrm{pH}$}

1\% solution of Polyherbal formulation was prepared in distilled water and $\mathrm{pH}$ was determined using digital $\mathrm{pH}$ meter [table 3].

\section{Fluorescence analysis}

Fluorescent characteristics of powdered plant material with different chemical reagents were determined under ordinary and ultraviolet light according to the procedure of Kokoshi et al. [13$14] .10 \mathrm{mg}$ of the formulation was taken in a glass slide and treated with various reagents for the presence of their fluorescence characteristics under ultra-violet lamp at 254 and $366 \mathrm{~nm}$.

\section{Determination of physical characteristics \\ Determination of viscosity and density}

Density, surface tension and viscosity of the $1 \%$ aqueous traditional formulation was estimated.

\section{Bulk density}

It is the ratio of given mass of powder and its bulk volume. It is determined by transferring an accurately weighed amount of powder sample to the graduated cylinder with the aid of a funnel. The initial volume was noted. The ratio of the weight of the volume it occupied was calculated [15].

Bulk density $=\mathrm{W} / \mathrm{V}_{0} \mathrm{~g} / \mathrm{ml}$

Where, $\mathrm{W}=$ mass of the powder, $\mathrm{V}_{0}=$ untapped volume

\section{Tapped density}

It is measured by transferring a known quantity (25g) of powder into a graduated cylinder and tapping it for a specific number of times. The initial volume was noted. The graduated cylinder was tapped continuously for a period of 10-15 min. The density can be determined as the ratio of the mass of the powder to the tapped volume.

Tapped volume $=\mathrm{W} / \mathrm{V}_{\mathrm{f}} \mathrm{g} / \mathrm{ml}$

Where, $\mathrm{W}=$ mass of the powder, $\mathrm{V}_{\mathrm{f}}=$ tapped volume.

\section{Compressibility index}

It is the propensity of the powder to be compressed. Based on the apparent bulk density and tapped density the percentage compressibility of the powder can be determined using the following formula.

Compressibility index $=\left[\left(\mathrm{V}_{0}-\mathrm{V}_{\mathrm{f}}\right) / \mathrm{V}_{0}\right] \times 100$,

Or \% Compressibility $=[($ tapped density-bulk density $)] /$ tapped density] x 100

\section{Hausner ratio}

It indicates the flow properties of the powder. The ratio of tapped density to the bulk density of the powder is called Hausner ratio.

Hausner ratio= Tapped density/bulk density.

\section{Preliminary phytochemical analysis}

A successive extraction of TF was carried out with different solvents such as hexane, ethyl acetate, methanol, ethanol and water (non-polar to polar). The extract was subjected to preliminary phytochemical screening of various plant constituents according to Kokate [16].

Quantitative determination of total phenolic, flavonoid and alkaloid content

\section{Total phenol determination}

The total phenolic content was estimated using the modified Folin Ciocalteu photometric method with Gallic Acid as standard [17]. To $0.1 \mathrm{ml}$ of aqueous extract of TF in a test tube added $3.9 \mathrm{ml}$ of distilled water and $0.5 \mathrm{ml}$ of Folin Ciocalteu reagent and incubated at room temperature for $5 \mathrm{~min}$ after which $2 \mathrm{ml}$ of $20 \%$ sodium carbonate was added to it and kept in boiling water bath for $10 \mathrm{~min}$. Phenol reacts with the phosphomolybdic acid in the Folin Ciocalteu reagent in alkaline medium and produces a blue coloured complex which is read at $650 \mathrm{~nm}$. The total phenolic content is expressed as Gallic acid equivalents (GAE) per $\mathrm{g}$ of dry weight (DW). The experiments performed thrice and the results shown in table 7.

\section{Total alkaloid determination}

The total alkaloid content was determined according to UVSpectrophotometer method [18].1g of TF was weighed into a $50 \mathrm{ml}$ beaker and dispersed into $40 \mathrm{ml}$ of $10 \%$ acetic acid solution in ethanol. The filtrate was then evaporated to one-quarter of its original volume on a hot plate. Concentrated ammonium hydroxide was added dropwise in order to precipitate the extract. The whole 
solution was allowed to settle and the precipitate was collected and washed with dilute ammonium hydroxide and then filtered. The residue is the alkaloid which was dried and weighed.

\section{Total flavonoid determination}

Total flavonoid content was determined by the spectrophotometric method. $1 \mathrm{ml}$ of TF extract and a standard solution of rutin was added to $10 \mathrm{ml}$ volumetric flask containing $4 \mathrm{ml}$ of distilled water. To this 0.3 $\mathrm{ml}$ of $5 \% \mathrm{NaNo}_{2}$ was added. After $5 \mathrm{~min}, 0.3 \mathrm{ml}$ of $10 \% \mathrm{AlCl}_{3}, 2 \mathrm{ml}$ of 1 $\mathrm{M} \mathrm{NaOH}$ was added and the total volume was made up to $10 \mathrm{ml}$ with distilled water. The solution was mixed well, and the absorbance was measured against prepared reagent blank at $510 \mathrm{~nm}$. The value of optical density was used to calculate the total flavonoid content against the different concentration of standard rutin. The flavonoid content was expressed in terms of rutin (mg of RU/g of dried weight DW) $[19,20]$. The experiments performed thrice and the results shown in table 7.

\section{Total tannin determination}

The total tannins were estimated by the Folin Dennis method. 100ul of TF extract was made up to $10 \mathrm{ml}$ with distilled water. To this $1 \mathrm{ml}$ of Folin Denis reagent and $2 \mathrm{ml}$ of Sodium carbonate was added. The absorbance was read at $700 \mathrm{~nm}$ after $30 \mathrm{~min}$. Water was used as a blank instead of the sample. The calibration curve was obtained for different concentration of standard tannic acid. The quantity of the tannins present in the aqueous extract of the samples was calculated as mg equivalent of Tannic acid (TA) [21]. The experiments performed thrice and the results shown in table 7 .

\section{RESULTS}

Traditional formulation (TF) was subjected to a various analytical procedure to validate the physical and physiochemical properties of the drug. The composition of the traditional siddha formulation was shown in table 1.

\section{Organoleptic assessment}

Table 2 shows the organoleptic character of the drug with greenish color, slightly bitter taste and characteristic odour.

\section{Physiochemical properties}

Physiochemical properties of the drug like LOD, ash content, water-soluble extractive, acid insoluble extractive content and $\mathrm{pH}$ were found to be within pharmacopeial limits as shown in table 3.

\section{Physical characteristics}

A physical characteristic feature of the drug like density, surface tension, viscosity is shown in table 4.

\section{Fluorescent analysis}

In the present study dried powder treated with various reagents showed characteristic fluorescence at $254 \mathrm{~nm}$ and $366 \mathrm{~nm}$ wavelength as shown in table 5 .

\section{Preliminary phytochemical screening}

Primary Phytochemical screening is evaluated qualitatively in different solvent extraction is shown in table 6 and secondary metabolites like total phenol, flavonoid, tannin and alkaloid evaluated quantitatively which are helpful in predicting their therapeutic properties as shown in table 7. However, aqueous extract was found to show positivity to a maximum number of phytochemical constituents.

Table: 1 Composition of Traditional Formulations

\begin{tabular}{llll}
\hline S. No. & Plants & Family & Parts used \\
\hline 1. & Curcumina longa & Zingiberaceae & Rhizome \\
2. & Phylanthusamarus & Phyllanthaceae & Whole plants \\
3. & Wedeliachinensis & Asteraceae & Whole plants \\
4. & Terminaliachebula & Combretaceae & Pericarp \\
5. & Terminaliabellirica & Combretaceae & Fruits \\
6. & Embellicaofficinalis & Euphorbiaceae & Fruits \\
7. & Cuminiumcyminum & Apiaceae & Seeds \\
\hline
\end{tabular}

Table 2: Organoleptic properties of traditional formulation

\begin{tabular}{ll}
\hline Appearance & Powder \\
\hline Color & Greenish brown \\
Odour & Characteristic \\
Taste & Slightly bitter \\
Particle size & $100 \#$ sieve \\
Texture & Fine \\
\hline
\end{tabular}

Table 3: Physiochemical characteristics of traditional formulation

\begin{tabular}{lll}
\hline S. No. & Parameter & Percentage \\
\hline 1. & Loss on drying (LOD) (w/w \%) & $11 \%$ \\
2. & Water soluble extractive (w/w \%) & $42.6 \%$ \\
3. & Alcohol soluble extractive & $18.6 \%$ \\
4. & Ash content (w/w $\%)$ & $10.4 \%$ \\
5. & Acid insoluble ash (w/w \%) & $3.4 \%$ \\
6. & Water Soluble ash (w/w \%) & $8.2 \%$ \\
7. & Moisture content & $6.7 \%$ \\
8. & $\mathrm{pH}$ & 6.2 \\
\hline
\end{tabular}

Table 4: Physical characteristics

\begin{tabular}{lll}
\hline S. No. & Parameter & Value \\
\hline 1. & Density & 0.99 \\
2. & Viscosity & $1.00 \mathrm{cp}$ \\
3. & Bulk density & $0.474 \mathrm{~g} / \mathrm{ml}$ \\
4. & Tapped density & $0.582 \mathrm{~g} / \mathrm{ml}$ \\
5. & Carr's compressibility Index & 18.556 \\
6. & Hausner's ratio & 1.227 \\
\hline
\end{tabular}


Table 5: Fluorescence analysis

\begin{tabular}{llll}
\hline Formulation & Visible light & UV-Short 254 nm & UV-Long 366 nm \\
\hline TF & Greenish brown & Brown & Dark brown \\
TF+Petroleum ether & Dull yellow & Dark brown & Black \\
TF+Chloroform & Pale yellow & Faded brown & Yellowish brown \\
TF+Ethyl acetate & Pale yellow & Brownish yellow & Yellowish brown \\
TF+Acetone & Light yellow & Yellow & Dark yellow \\
TF+Ethanol & Yellowish brown & Dark yellow & Black \\
TF+Water & Greenish brown & Dark brown & Dark brown \\
TF+Conc. H2SO4 & Dark brown & Greenish Brown & Dark brown \\
TF+Conc. HCl & Greenish brown & Dark green & Black \\
TF+1N NaOH & Reddish Brown & Dark green & Black \\
TF+Ammonia & Greyish brown & Greenish brown & Brackish brown \\
\hline
\end{tabular}

Table 6: Preliminary phytochemical analysis

\begin{tabular}{|c|c|c|c|c|c|c|c|}
\hline S. No. & Phytoconstituents & Test name & Hexane & $\begin{array}{l}\text { Ethyl } \\
\text { acetate }\end{array}$ & $\begin{array}{l}\text { Methanol } \\
\text { extract }\end{array}$ & $\begin{array}{l}\text { Ethanol } \\
\text { extract }\end{array}$ & $\begin{array}{l}\text { Aqueous } \\
\text { extract }\end{array}$ \\
\hline \multirow[t]{3}{*}{1.} & Carbohydrates & Fehlings test & - & + & - & + & +++ \\
\hline & & Benedict test & - & + & + & ++ & +++ \\
\hline & & Molisch test & - & - & - & + & ++ \\
\hline \multirow[t]{3}{*}{2.} & Proteins and amino acids & Millon's test & - & - & - & + & ++ \\
\hline & & Biuret test & - & - & + & + & + \\
\hline & & Ninhydrin test & + & + & + & + & ++ \\
\hline 3. & Reducing sugars & Molisch test & - & - & + & + & ++ \\
\hline 4. & Saponins & Froth test & + & + & - & - & - \\
\hline 5. & Alkaloids & $\begin{array}{l}\text { Mayers test } \\
\text { Wagners test }\end{array}$ & - & + & + & + & ++ \\
\hline \multirow[t]{2}{*}{6.} & Tannins & Ferric chloride test & - & - & + & ++ & +++ \\
\hline & & Lead acetate test & - & - & + & + & ++ \\
\hline 7. & Flavanoids & Zinc chloride test & - & - & + & ++ & +++ \\
\hline 8. & Triterepenes & Chloroform test & - & - & ++ & + & - \\
\hline 8. & Anthraquinones & Borntragers test & + & + & - & - & - \\
\hline 9. & Steroids & Salkowski test & + & + & ++ & + & + \\
\hline 10. & Fixed oil and fats & & - & + & ++ & + & + \\
\hline 11. & Mucilage and gums & Alcoholic ppt. test & + & - & - & - & - \\
\hline 12. & Cardiac glycosides & Keller-kilianitest & - & - & - & + & ++ \\
\hline 13. & Starch & Iodine test & - & - & - & + & + \\
\hline
\end{tabular}

+++: Intense; ++: Moderate; +: Slight; -: Absent

Table 7: Quantitative analysis of secondary metabolites

\begin{tabular}{lll}
\hline S. No. & Bioactive compounds & Quantity \\
\hline 1. & Flavanoids & $7.1+0.14 \mathrm{mg}$ of RU/g of DW \\
2. & Alkaloids & $2.9+0.09 \mathrm{mg} / \mathrm{g}$ of DW \\
3. & Total Phenols & $6.5+0.12 \mathrm{mg}$ of GA $/ \mathrm{g}$ of DW \\
4. & Tannins & $4.8+0.07 \mathrm{mg}$ of TA/g of DW \\
\hline
\end{tabular}

*Values are means of triplicate determination+Standard deviation.

\section{DISCUSSION}

In recent years there are numerous medicinal plants and traditional formulations available for the treatment of many complicated diseases. Traditional Siddha formulation consists of 7 ingredients, viz., Curcuma longa Terminaliachebula, Terminaliabelerica, Emblicaofficinalis, Sphagneticolacalendulacea, Phyllanthusamarus and Cuminumcyminum. These plants have antibacterial, hepatoprotective, antihepatotoxic, uterine and intestine stimulating properties. Quality evaluation of formulations is a fundamental requirement of mankind. The process of standardisation can be achieved by stepwise pharmacognostic studies. The organoleptic assessment provides the simplest and quickest means to establish the identity and thereby ensure the quality of a particular sample and these features are useful in judging the material totally and in powder form [1]. The organoleptic character of the formulation shows greenish colour, slightly bitter taste and characteristic odour. Physico-chemical constants like ash value, water soluble extracts, alcoholic extracts, losson drying and $\mathrm{pH}$ values were determined as per method described in Indian Pharmacopoeia [2].
Ash value depends upon the inorganic substances present in the particular formulation. This may be useful in standardising the drugs. The ash value of formulation is $10.4 \%$. The acid insoluble ash value of the drug denotes the amount of siliceous matter in the plants. The quality of the drug is better if the insoluble acid value is low. It is $3.4 \%$ for formulation. Loss on drying indicates the total volatile content and moisture content of the formulation. High moisture content may affect the quality of drug and the less value of moisture content could prevent bacterial, fungal or yeast growth [12]. This formulation shows a loss on drying at $105 \mathrm{C}$ of $11 \%$ and moisture content of $6.7 \%$. The percentage of soluble constituents present in the drug is determined by the value of water and alcohol extractive. These values correlate with the metabolic reaction of the drug and helps in evaluating crude drugs [15]. The $\mathrm{pH}$ of $1 \%$ aqueous solution is 6.2 and found to be suitable for human use.

Bulk characterization is necessary to avoid misleading predictions of solubility or stability which depends on a particulate flowability of granules or powder. Bulk density and tapped density is useful for determination of packing of powder material. The bulk density and tap 
density of Traditional formulation (TF) were found to be comparable, and variation was insignificant as shown in table 4. Hausner's ratio was related to winter particulate friction and could be used to predict powder flow properties. It showed that powder with low interparticulate friction, had a ratio of approximately 1.22 whereas less free flowing powder such as flakes have Hausner's ratio greater than 1.6. This shows that the formulation powder has low winter particulate friction. The percentage compressibility of powder is Carr's index, a direct measure of a potential powder arch or bridge strength and stability [15]. If percentage compressibility is in the range of $28 \%-35 \%$ it shows fluid, cohesive powder, in our study, the percentage compressibility of formulations indicates that formulations are less cohesive.

The fluorescent characteristic of powdered drug plays a vital role in the determination of quality and purity of the drug material. Some constituents show fluorescence in the visible range in daylight. The ultraviolet light produces fluorescence in many natural products which do not visibly fluorescence in daylight. If substance themselves are not fluorescent, they may often be converted into fluorescent derivatives or decomposition products by applying different reagents [13]. Hence crude drugs are often assessed qualitatively in this way and it is an important parameter for pharmacognostic evaluation of crude drugs.

Medicinal plant extracts are reported to have health beneficial properties that are due to secondary metabolites such as phenolics, flavonoids, glycosides, alkaloids, tannins, saponins, anthraquinones, etc., present in them. These bio-components are known for their versatile biological effects and are implicated in the treatment of a variety of diseases. The screening of phytochemicals in TF was clearly validated in this study. Aqueous extract of formulation shows the adequate presence of phytoconstituents than the alcohol and methanol extract.

Flavonoids and Total phenols are abundantly present in the aqueous extract of TF. The flavonoids and phenolic compounds reported exerting multiple biological effects including antioxidant, free radical scavenging abilities, anti-inflammatory, anti-carcinogenic activity. Phenolics are one of the major largest and most ubiquitous groups of plant metabolites that can be found ubiquitously in certain plants [16], which are considered as bioactive and non-nutritional compounds, due to their antioxidant properties, against free radicals effects that exhibit various significant biological activities. Flavonoids are hydroxylated phenolic substances known to be synthesised by plants in response to microbial infection and they have been found to be antimicrobial substances against a wide array of microorganism in vitro [18]. They are also an effective antioxidant and exhibit stronger anticancer, cardiovascular activities. Flavonoids are capable of treating certain physiological disorder and diseases [19]. Tannins are considered as superior antioxidants as they prevent cellular damages by shielding the proteins from oxidation and glycation reactions, besides their copper scavenging action [20]. The soothing effect of tannins on vascular segments indicates their protective effect in hepatocellular complications [21]. Alkaloids have been shown to exhibit a cytotoxic effect on tumour cell lines emphasising its role in the prevention of cancer, neurodegenerative diseases, chronic inflammation, etc [22].

\section{CONCLUSION}

The present investigation is carried out to meet the requirements of WHO and other regulatory bodies concerning standardisation of natural origin products on the same pattern as synthetic drugs. The present studies show that organoleptic character, physiochemical and physical properties of traditional formulations falls within the permissible limits as per WHO. The therapeutic potential of the formulation may be due to the presence of various phytochemicals present in the aqueous extract. Further studies are to be carried out with different analytical and biochemical parameters and also by in vivo methods.

\section{CONFLICT OF INTERESTS}

\section{Declared none}

\section{REFERENCES}

1. Jarald EE. Textbook of pharmacognosy and phytochemistry. 1st ed. CBS publication, Delhi; 2009.
2. Indian Pharmacopoeia. Vol III. Controller of Publications, Ghaziabad; 2007. p. 2034-57.

3. World Health Organization (WHO). Quality Control Methods for Medicinal Plant Materials. AITBS Publishers, Delhi; 2002. p. 46-51.

4. Badugu LR. Phytochemical screening, quantitative estimation total phenolics and total flavonoids, anti-microbial evaluation of Cyamopsistetragonoloba. Int J Res Pharm Biomed Sci 2012;3:1139-42.

5. Parekh J, Karathia N, Chanda S. Evaluation of antibacterial activity and phytochemical analysis of Bauhinia variegata $\mathrm{L}$. bark. Afr J Biomed Res 2006;9:53-6.

6. Shanmugapriya K, Saravana PS, Payal H, Mohammed P, Binnie W. A comparative study of antimicrobial potential and phytochemical analysis of Artocarpusheterophyllusand Manilkarazapotaseed extracts. J Pharm Res 2011;4:2587-9.

7. Kalaiselvan V, Kalpeshkumar SA, Patel FB, Shah CN. Quality assessment of different marketed brands of Dasamoolaristam, an ayurvedic formulation. Int J Ayurveda Res 2010;1:10-1.

8. Vaidya Ratnam KS, Murugesa Mudaliar. Gunapadam. (Siddha Materia Medica) $1^{\text {st }}$ edition; 1936. p. 229,345,459,520,720.

9. Tharakan Sheeja T, Kuttan Girija, Kuttan Ramadasan, Kesavan, Austin. Immunostimulatory action of AC II--an ayurvedic formulation useful in HIV. Indian J Exp Biol 2008;46:47-51.

10. Siddiqui, Hakim MA. Format for the pharmacopoeial analytical standards of compound formulation, workshop on standardization of Unani drugs, (appendix), New Delhi: Central Council for Research in Unani Medicine (CCRUM); 1995.

11. Kokate CK, Purohit AR, Gokhale SB. Pathway to Screen Phytochemical nature of Natural Drugs. Pharmacognosy. 42nd ed. Pune, Nirali Prakashan; 2008. p. 56-61.

12. Srivastava NK, Shreedhara CS, Aswatha Ram HN. Standardisation of Ajmodadichurna, a polyherbal formulation. J Pharmacogn Res 2010;2:98-101.

13. Kokoshi CJ, Kokski RJ, Sloma FJ. Methods for the analysis of various compound in plants. J Pharmacogn Assoc 1958;10:716.

14. Chase CR, Pratt RJ. Fluorescence of powdered vegetable drugs with particular reference to the development of a system of identification. J Am Pharm Assoc 1949;38:324-31.

15. Rakesh S Shivatare, Ashish S Pande, Hanumant U Bhusnar, Prasad V Kadam, Kavita N Yadav, et al. Standardization of narasimha churna: a poly-herbal formulation. Asian J Biomed Pharm Sci 2013;3:23-7.

16. Singleton VL, Orthofer R, Lamuela-Raventos RM. Analysis of total phenols and other oxidation substrates and antioxidants by means of folin-ciocalteau reagent. Methods Enzymol 1999;299:152-78.

17. Adeniyi SA, Orjiekwe CL, Ehiagbonare JE. Determination of alkaloids and oxalates in some selected food samples in Nigeria. Afr J Biotechnol 2009;8:110-2.

18. Zhishen J, Mengcheng T, Jianming $\mathrm{W}$. The determination of flavonoid contents in mulberry and their scavenging effects on superoxide radicals. Food Chem 1999;64:555-9.

19. Zou Y, Lu Y, Wei D. Antioxidant activity of a flavonoid-rich extract of Hypericumperforatum L in vitro. J Agric Food Chem 2004;52:5032-9.

20. Hussain J, Jamila N, Gilani SA, Abbas G, Ahmed S. Platelet aggregation, antiglycation, cytotoxic, phytotoxic and antimicrobial activities of extracts of Nepetajuncea. Afr J Biotechnol 2009;8:935-40.

21. VC Devaraj, B Gopala Krishna, GL Viswanatha. Hepatoprotective activity of Hepax-A polyherbal formulation. Asian Pac J Trop Biomed 2011;1:142-6.

22. Shrivastava Surabhi, Leelavathi S. Preliminary phytochemical evaluation of leaf extracts of catunaregumspinosa thunb. Int J Pharm Sci Rev Res 2010;3 :100-8.

\section{How to cite this article}

- Sri Kamatchi Priya Ramamoorthy, Diwakar Manickam, Samu Subramaniam, Shyama Subramaniam. Standardisation and phytochemical screening of traditional formulation. Int J Curr Pharm Res 2017;9(1):70-74. 